\title{
EL ORIENTALISMO EN LA PRODUCCIÓN CERÁMICA DE WILLIAM DE MORGAN (1839-1917): LAS CORRIENTES PERSA, IZNIK Y ANDALUSÍ
}

\author{
The Orientalism in the Ceramic Production of William de Morgan \\ (1839-1917): The Persian, Iznik and Andalusí Currents
}

\author{
Guillermo Juberías Gracia ${ }^{1}$ \\ guillermojuberias@gmail.com \\ Universidad de Zaragoza. España \\ Fecha de recepción: 01/05/2020 \\ Fecha de aceptación: 05/06/2020
}

\begin{abstract}
Resumen: Un periodo clave para el estudio de la historia del diseño contemporáneo fue la segunda mitad del siglo XIX, momento en el que se desarrolló en Gran Bretaña el movimiento de las Arts \& Crafts, impulsado por William Morris. Curiosamente, uno de sus colaboradores más cercanos, el ceramista William de Morgan (1839-1917), no ha recibido demasiada atención por parte de los investigadores. A través del presente artículo aportamos nuevas visiones sobre su cerámica inspirada en la tradición islámica, contextualizando la creación de sus piezas en un momento de auge del Orientalismo. Fue, precisamente entonces, cuando numerosas colecciones públicas y privadas británicas se enriquecieron con valiosos ejemplares de cerámica procedente de la antigua Persia, del Imperio Otomano o de España. Las publicaciones existentes sobre William de Morgan no analizan en qué medida estos influjos determinaron su producción, cuestión que abordamos en el presente estudio. Para ello hemos utilizado documentos como su discurso sobre la cerámica de reflejo metálico presentado a la Royal Society of Arts en 1892, así como multitud de sus diseños conservados en los fondos del Victoria and Albert Museum de Londres (V\&A). De esta manera hemos podido profundizar sobre el impacto del Orientalismo en la cerámica decimonónica, poniendo en valor la relevancia que los antiguos diseños persas, otomanos y andalusíes tuvieron a la hora de renovar las artes decorativas europeas.
\end{abstract}

${ }_{1}^{1}$ Miembro del grupo de investigación consolidado Observatorio Aragonés de Arte en la Esfera Pública, dirigido por el profesor Jesús Pedro Lorente. El autor agradece la ayuda prestada por las profesoras María Pilar Poblador Muga y María Isabel Álvaro Zamora en la elaboración de este trabajo. 
Palabras clave: Orientalismo; Arts \& Crafts; arte islámico; cerámica; William de Morgan; Victoria and Albert Museum.

Abstract: A key period for the study of the history of contemporary design was the second half of the 19th century, when the Arts \& Crafts movement was developed in Great Britain, promoted by William Morris. Interestingly, one of his closest collaborators, the potter William de Morgan (18391917), has not received much attention from researchers. Through this paper, we contribute with new visions of its pottery inspired by the Islamic tradition, contextualizing the creation of its pieces at a time of boom in Orientalism. It was precisely then that several British public and private collections were enriched with precious ceramic objects from ancient Persia, the Ottoman Empire or Spain. The existing publications on William de Morgan do not analyze how these influences determined his production, a question that we address in the present study. In order to achieve this goal, we have used documents as his discourse on lustre ware ceramics presented to the Royal Society of Arts in 1892, as well as many of his designs hoarded in the collections of the Victoria and Albert Museum in London (V\&A). In this way we have been able to delve into the impact of Orientalism on nineteenth-century ceramics, highlighting the relevance that ancient Persian, Ottoman and Andalusian designs had when it came to renovating European decorative arts.

Keywords: Orientalism; Arts \& Crafts; islamic art; ceramics; William de Morgan; Victoria and Albert Museum.

SUMARIO: 1. La fascinación por la cerámica de tradición islámica en la Inglaterra victoriana. 2. William de Morgan: un renovador del arte decorativo británico. 3. Glazed pottery: diseños de inspiración islámica en la obra de William de Morgan. 4. Conclusiones. 5. Referencias bibliográficas.

\section{LA FASCINACIÓN POR LA CERÁMICA DE TRADICIÓN ISLÁMICA EN LA INGLATERRA VICTORIANA}

Una de las manifestaciones más destacadas del orientalismo decimonónico fue la del coleccionismo de ricos objetos de tradición islámica. Este interés por la cultura y el arte musulmán arrancó en época del Romanticismo y tuvo una larga continuidad hasta entrado el siglo xx. En Inglaterra, la llegada de piezas procedentes de países como España, Turquía, Egipto o Siria tuvo lugar sobre todo durante la época victoriana (1837-1901), coincidiendo con un anhelo de renovación y de búsqueda de nuevas referencias artísticas, tal y como pudo comprobarse en la primera exposición universal celebrada en Londres en 1851 (De Guise, 2008, p. 69).

Para comprender el contexto de renovación del diseño en el que fue producida la cerámica de William de Morgan, es importante recordar cómo Inglaterra fue, desde el siglo XVIII, puntera en el proceso de industrialización. Esto contribuyó a que, durante la siguiente centuria, llegase a ser la primera potencia económica del mundo. Sin embargo, esta prosperidad escondía una situación desfavorable de las clases obreras, hacinadas en residencias insalubres y sometidas a unas duras condiciones labores. En este momento nacen las sociedades de amigos, integradas por empleados de un mismo gremio, constituidos en cooperativas en las que se luchaba 
por mejorar la vida de los obreros. Al mismo tiempo, la burguesía fue cada vez más determinante, integrada por los nuevos propietarios y directivos industriales y por la red de altos funcionarios y diplomáticos que buscaban asegurar el funcionamiento de las estructuras del Imperio Británico (Woodward, 1982). La formación de estos profesionales en escuelas privadas incluía el paso por las facultades de Oxford o Cambridge, donde se dedicaban al estudio del pasado y de las lenguas clásicas, logrando una sólida formación humanística (Townson, 2004, pp. 370-397). Entre esta juventud burguesa de amplia cultura se encuentran algunos de los personajes más destacados de las artes y la literatura inglesas de la época victoriana, incluyendo al propio William de Morgan.

El auge industrial vino ligado al desarrollo del diseño, sin embargo, a partir de los años 30 del siglo XIX se apreció un decaimiento en la calidad de las producciones industriales, lo que dio lugar a un cierto escepticismo acerca de la calidad del arte decorativo británico (Greenhalgh, 2000, pp. 127-145). Por este motivo surgieron diseñadores que plantearon nuevas vías de producción en las que el arte y la industria no fuesen enemigos, consiguiendo piezas de mayor calidad, capaces de llegar a un espectro social mayor, no solamente a las clases adineradas (De Fusco, 2005, pp. 57-98).

En esta búsqueda de nuevas soluciones ante la diatriba entre industria y arte, sobresale la personalidad de Henry Cole (1808-1882). A él debemos el concepto de art manufacturer, un antecedente del artista diseñador. Fue además un personaje clave para la historia del diseño y del coleccionismo en Inglaterra, pues fue uno de los artífices de la Exposición Universal de Londres de 1851, creando un año después un museo de manufacturas y arte decorativo. Siguiendo los postulados de John Stuart Mill, concedió a los objetos una atención que hasta entonces no habían recibido, buscando su utilidad a la vez que considerándolos como parte de las Bellas Artes.

En esta renovación del arte industrial y en la formación de futuros diseñadores cobró importancia el estudio de repertorios artísticos de otras épocas y culturas. Aquí jugaron un rol fundamental los diseños recogidos por Owen Jones en su Grammar of Ornament, en donde el artista británico identificó y calcó multitud de patrones extraídos del arte islámico. Llegó a crear en los años 40 del siglo XIX sus propios diseños de azulejos a partir de la copia de detalles de cerámicas que pudo estudiar en El Cairo (Newton, 1999, p. 90), tal y como se aprecia en varios diseños realizados a la acuarela, conservados en el V\&A (8115:1-15)

Relacionado con este interés por el diseño, existió un coleccionismo de cerámica de tradición musulmana en la Inglaterra victoriana, un fenómeno clave para comprender las fuentes de inspiración de William de Morgan. En 1857 la reina Victoria inauguraba el South Kensington Museum, como fue denominado hasta 1899 el

2 Para facilitar su identificación, a lo largo del artículo se presentan los números de inventario de las obras citadas pertenecientes a la colección del V\&A. Las piezas son consultables en: https://collections.vam.ac.uk/ (fecha de consulta: 02-04-2020). 
V\&A. Cole fue su director y la finalidad de la institución fue conformar la mayor colección de artes decorativas del mundo, que además constituyese un muestrario para los estudiantes y para los profesionales del diseño industrial. Desde sus inicios, el museo se interesó por la cerámica de tradición islámica, adquiriendo piezas de gran valor a través de agentes y marchantes distribuidos por todo el mundo. En pocos años, la cuantía de la colección era considerable, lo que llevó a realizar el primer catálogo de estas piezas, encargado a Charles Drury Edward Fortnum (1820-1899) ${ }^{3}$, titulado A descriptive catalogue of the maiolica, Hispano-Moresco, Persian, Damascus, and Rhodian wares in the South Kensington Museum: with historical notes, marks, \& monograms (1873). Para comprender la gestación de esta rica colección es necesario aludir brevemente a los agentes que trabajaron para el museo localizando piezas en varios países, manteniendo perfiles a caballo entre el marchante, el coleccionista y el experto.

Para el enriquecimiento de las colecciones de cerámica persa fue fundamental la labor de Robert Murdoch Smith (1835-1900), quien trabajó desde 1865 como director de la Persian Telegraph Company y estuvo, desde los años 70, al servicio del departamento de Arte y Ciencia del gobierno británico para la adquisición de antigüedades en el país. Irán poseía una rica tradición de cerámica esmaltada de aplicación arquitectónica, la cual alcanzó un desarrollo extraordinario durante el periodo del Ilkanato persa (1256-1335). Estos azulejos fueron el objetivo de sucesivas compras por parte de ingleses y franceses asentados en el país, contando habitualmente con la aprobación de los gobiernos locales, de hecho, el propio gobierno persa mostró las piezas adquiridas por estos coleccionistas en las exposiciones internacionales de París (Masuya, 2000, pp. 39-54). Para 1876, Smith expuso su colección de objetos persas en el South Kensington Museum, con casi un millar de azulejos antiguos. Ese mismo año, el museo adquirió una parte considerable del acervo de Smith, enriqueciéndolo durante las siguientes décadas. Tal y como explicamos más adelante, De Morgan conocía bien la cerámica persa y las publicaciones del propio Robert Murdoch Smith.

El segundo tipo de cerámica de tradición islámica muy apreciado en Inglaterra fue la cerámica Iznik, procedente del Imperio Otomano. Este tipo de cerámica recibió el nombre de la ciudad en la que comenzó a ser fabricada, la antigua Nicea griega, en el noroeste de Anatolia. Con antecedentes en el siglo XIV, los primeros ejemplos de calidad de este tipo de piezas son de finales del siglo $\mathrm{xV}$, alcanzando durante el siglo siguiente un altísimo nivel de perfeccionamiento, lo que convirtió a estos objetos en una mercancía muy preciada en la Inglaterra victoriana. La principal particularidad de esta cerámica es la utilización de motivos decorativos extraídos de la cerámica blanca y azul china, al ser piezas coleccionadas por los sultanes otomanos gracias a la Ruta de la Seda. Hacia mediados del siglo XVI, los colores de la cerámica Iznik alcanzaron

${ }^{3}$ Incluimos la fecha de nacimiento y defunción de aquellos personajes especialmente relevantes para nuestro tema de estudio. 
su mayor esplendor, consiguiendo rojos intensos, azules cobalto y verdes salvia que destacaban sobre los fondos de un blanco perfecto (Carswell, 2006 y Denny, 2004).

En la Inglaterra de mediados del XIX, este tipo de cerámica comenzó a ser conocida gracias a establecimientos comerciales especializados en la venta de cerámica blanca y azul, china casi siempre, pero en ocasiones también otomana. Pintores como Dante Gabriel Rossetti o James Whistler coleccionaron estos objetos, actuando frecuentemente como intermediarios en su venta a otros artistas de su círculo de amigos. Curiosamente, la similitud entre algunas piezas otomanas y chinas hizo que la clientela británica confundiese sus orígenes, surgiendo cierta confusión en la época. Así sucedió con el acervo de George Salting, uno de los mejores coleccionistas de cerámica islámica en la Inglaterra victoriana. De hecho, cuando Fortnum redactó el catálogo de loza y azulejo islámico del South Kensington Museum, dio a muchas piezas Iznik la denominación de cerámicas al estilo de Damasco, ciudad que era en aquella época parte del Imperio Otomano y cuyos edificios se ornamentaron ocasionalmente con cerámica procedente de Iznik. Un buen muestrario de estas colecciones particulares pudo contemplarse en la Exhibition of Persian and Arab Art organizada por el Burlington Fine Arts Club en 1885 (Gadoin, 2012).

La formación de las colecciones de cerámica española antigua y contemporánea del South Kensington Museum se debió en buena medida a la figura de Juan Facundo Riaño (1829-1901). El primer conservador del museo, John Charles Robinson, ya manifestó un claro interés hacia el arte español viajando a la Península Ibérica en 1863,1865 y 1879, adquiriendo numerosas obras de arte. Durante los años 70 y 80 , Riaño asesoró al museo informando de la venta de piezas de arte decorativo español fundamentalmente cerámica, joyería, textiles, mobiliario y platería (Trusted, 2010, p. 78). En 1872 publicó un estudio titulado Classified and Descriptive Catalogue of the Art Objects of Spanish Production in the South Kensington Museum. Para entonces los fondos del museo contaban con una rica colección de cerámica española, entre cuyas piezas hemos contabilizado más de cuarenta objetos catalogados como cerámica hispano-mauresque o moorish, casi todos fechados entre los siglos XIV y XVI. Además, muchas de estas piezas -entre las que podemos distinguir varias tipologías como cuencos, platos, albarelos, aguamaniles, tinajas y azulejosse caracterizan por ser lozas doradas y esmaltadas con reflejos metálicos, el tipo de cerámica española de tradición islámica más apreciado en Inglaterra en esta época, por su carácter vistoso y lujoso y por su perfección técnica. Para la adquisición de estos objetos Riaño tenía buenos contactos distribuidos por la geografía española, entre ellos podemos destacar a Federico Valera, de Fuente Nueva, Granada, que vendió en 1872 al museo seis azulejos de comienzos del XVI, con diseños que imitaban los de la Alhambra (Trusted, 2008, p. 215).

Debemos contextualizar la llegada de toda esta cerámica en un momento en el que el South Kensington Museum recopiló numerosas piezas de arte islámico español, prestando especial atención al periodo nazarí, encargando copias y vaciados en 


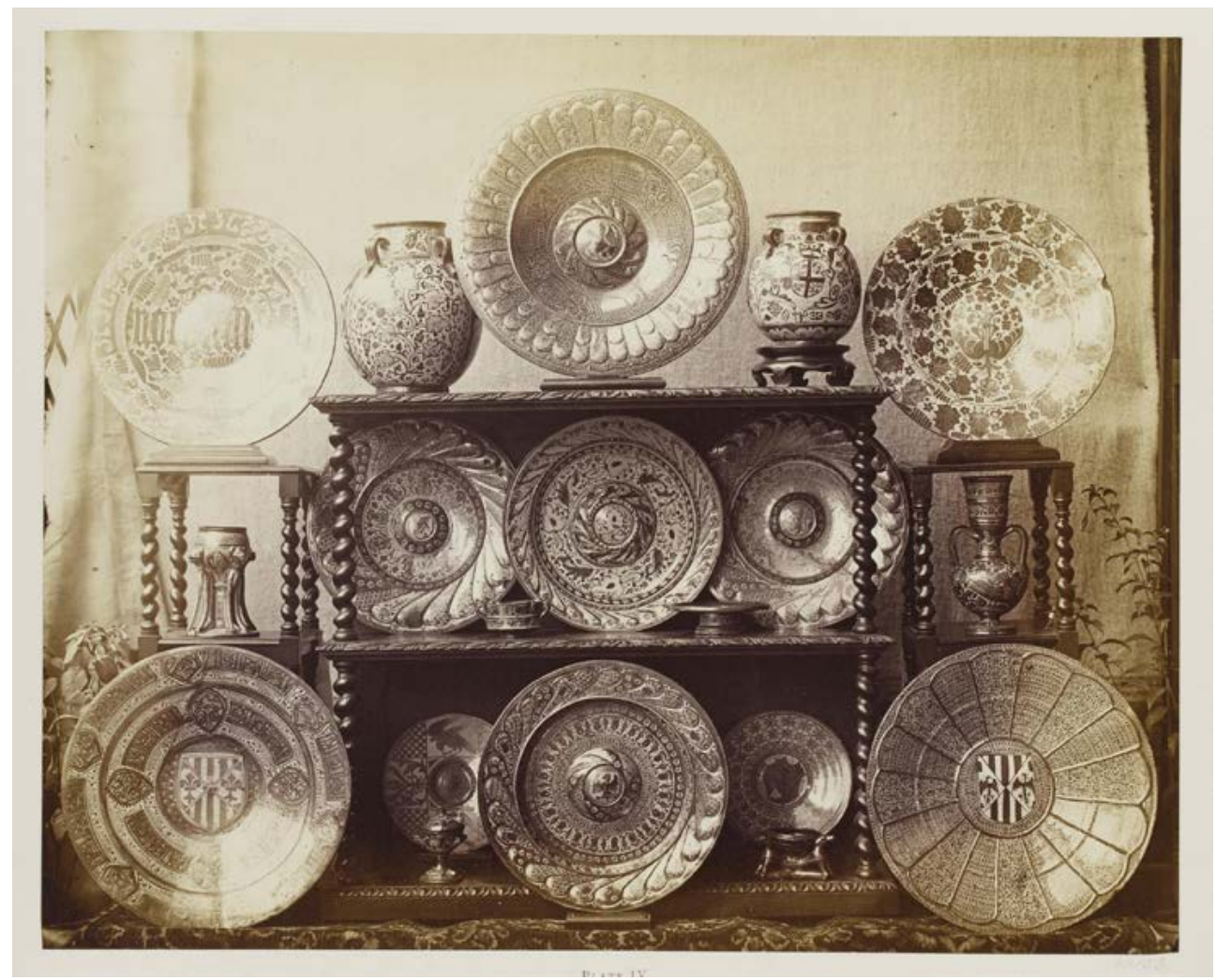

Fig. 1. Cerámica de Manises perteneciente a la colección de J. Henderson (ca. 1868). Cundall \& Fleming. Fotografía gentileza del @ Victoria and Albert Museum, London.

yeso de inscripciones y elementos arquitectónicos de la Alhambra y coleccionando maquetas del edificio (Raquejo, 1988, pp. 201-244 y González Pérez, 2017, pp. 6994). Además, en esta época, coleccionistas particulares británicos se hicieron con piezas de cerámica andalusí, como apreciamos en las fotografías encargadas hacia 1868 por el South Kensington Museum de la colección de John Henderson, elaboradas por la firma fotográfica Cundall \& Fleming (60153, Fig. 1). Todo ello refleja la fascinación que el arte hispanomusulmán ejerció en el ámbito anglosajón.

Por otra parte, el interés por la cerámica de tradición islámica no fue un fenómeno exclusivamente británico. Lo apreciamos claramente en la pintura orientalista del siglo XIX, una moda con seguidores en Francia -siendo practicada por maestros del academicismo como Gérôme o Laurens-, Gran Bretaña -a través de viajeros románticos como John Frederick Lewis o David Roberts-, Italia -como apreciamos en la pintura de Giulio Rosati- o España -con Josep Tapiró o el propio Mariano Fortuny-. La cerámica Iznik, por su difusión por el Mediterráneo Oriental, desde Estambul hasta El Cairo, pasando por Damasco, fue habitualmente representada por estos artistas, deseosos de dar a sus obras una erudición arqueológica. Si buena 


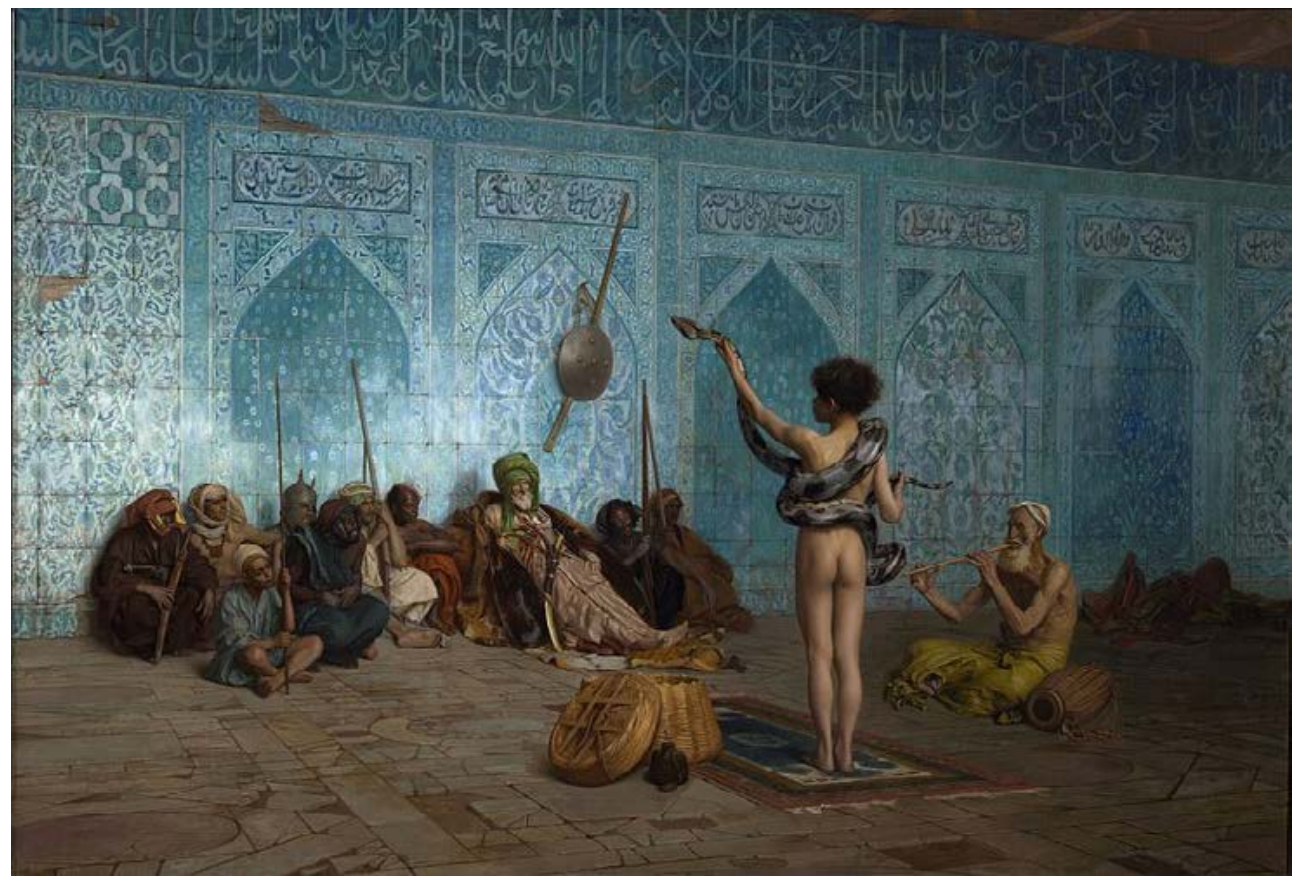

Fig. 2. The snake charmer (ca. 1879). Jean-Léon Gérôme. Sterling and Francine Clark Art Institute, Williamstown, Massachusetts. Dominio público.

parte de los escenarios representados por estos pintores eran composiciones artificiales -recreadas a partir de apuntes realizados durante algún viaje al Magreb o al Imperio Otomano, o utilizando fotografías y postales a la venta en estos países para los viajeros occidentales-, algunas de ellas demuestran un estudio minucioso del arte islámico. Independientemente de su verismo, estas pinturas contribuyeron a la valoración de las artes decorativas islámicas en Europa, convirtiendo a los objetos representados en ellas en auténticas joyas al alcance de unos pocos coleccionistas adinerados. Jean-Léon Gérôme utilizó las cerámicas Iznik en la ambientación de algunas de sus obras más célebres, como por ejemplo El encantador de serpientes (ca. 1879, Fig. 2). Tal y como apuntó Walter B. Denny, el panel de cerámicas representado por el pintor francés corresponde a la mezquita de Rustem Pasha en Estambul, a pesar de que los encantadores de serpientes no fuesen propios de la cultura otomana. Por aquel entonces, el Musée Cluny de París ya tenía una rica colección de piezas Iznik gracias a la adquisición del legado del fotógrafo y anticuario alsaciano Auguste Salzmann. Sus piezas fueron estudiadas por el ceramista francés Théodore Deck (1823-1891), cuya producción fue muy apreciada en la decoración de interiores francesa de finales del XIX (Deguise, 2008, p. 82).

Para comprender la utilización de motivos decorativos de las cerámicas persas, otomanas e hispanomusulmanas por parte de William de Morgan, es necesario aludir a los postulados estéticos imperantes en el diseño y la decoración de interiores en 
la Inglaterra victoriana. En primer lugar, debemos referirnos al proyecto de William Morris, junto a Cole, la cabeza de la renovación del diseño en la Inglaterra victoriana. En 1861 nació su empresa, la Morris, Marshall, Faulkner \& Co, para cuya fundación escribió un folleto explicativo en el que ya manifestó los ideales de las Arts \& Crafts. Desde 1888 organizó las exposiciones de artes y oficios, tomando como referencia los gremios y los procesos creativos de la Edad Media, una época idealizada durante el periodo victoriano, la cual según John Ruskin -maestro de Morris y otro de los ideólogos del movimiento- se caracterizaba por la honestidad de las relaciones sociales y por el uso sincero de los materiales. De Morgan trabajó para William Morris y, como consecuencia de su cercanía, apreciamos en sus obras muchos de los postulados del diseñador. Además, el carácter simétrico de los motivos decorativos de los azulejos y piezas islámicas era muy próximo a las creaciones de Morris, constituyendo una fuente de inspiración imprescindible para el ceramista.

Estas piezas de inspiración islámica adornaron los interiores de las mansiones inglesas, en consonancia con el esteticismo triunfante en la pintura y las artes decorativas del periodo. En esa época, bajo la noción de la beautiful house, tanto la alta sociedad como los propios artistas enriquecidos debido al éxito de sus propias empresas, acumularon en sus respectivas residencias suntuosos objetos manufacturados. En la segunda mitad del XIX surgió un gran interés por las casas de estos artistas, en las que el estudio aparecía como un sanctasanctórum, repleto de objetos lujosos importados de los confines del mundo. Poesías como The Palace of Art, de Tennyson, describen todos estos opulentos talleres, también recogidos por Mary Eliza Haweis en Beautiful Houses: Being a Description of Certain Well-known Artistic Houses (1882). Casas de artistas como la Leighton House (Londres) o residencias privadas de la burguesía como Wightwick Manor (West Midlands), Standen House (West Sussex) albergan obras diseñadas por William de Morgan, perfectamente contextualizadas en interiores a caballo entre los diseños Arts \& Crafts y la sofisticación del Aesthetic Movement. En mitad de este mobiliario victoriano encajan a la perfección los diseños de De Morgan inspirados en azulejos Iznik o persas, como apreciamos en las chimeneas de Cannon Hall (South Yorkshire) o de Glesnner House (Chicago), siendo este último un buen ejemplo de cómo esta moda llegó a Estados Unidos.

\section{WILLIAM DE MORGAN: UN RENOVADOR DEL ARTE DECORATIVO BRITÁNICO}

Para poder comprender las piezas creadas por William de Morgan bajo el influjo de la tradición islámica, es necesario hacer un breve recorrido por las etapas de su producción creativa. No podemos desvincular el diseño de estas obras de las importantes innovaciones técnicas conseguidas por su autor, basadas en buena medida en la investigación de la cerámica histórica. 
William de Morgan nació en 1839 en la capital británica, en el seno de una familia de posición acomodada. Su padre, Agustus de Morgan, fue un célebre matemático, profesor de la London University y su madre, Sophia Elizabeth Frend, fue una escritora de gran bagaje cultural (Hamilton, 1997, pp. 5-21). Estos orígenes burgueses parecían determinar su formación en alguna prestigiosa universidad del país, sin embargo, aunque intentó seguir la carrera de estudios clásicos en el University College de Londres, pronto la abandonó para entrar a la escuela privada de John Stephen Carry y posteriormente a la Royal Academy School. Aunque el rígido sistema académico no gustó al artista, los años de formación le permitieron orientar su especialización hacia las artes industriales y moverse en un círculo de jóvenes intelectuales y creadores entre los que se encontraba Henry Holiday, un pintor y decorador que formó parte del grupo prerrafaelita. Fue él quien presentó a Morris y a De Morgan en 1863, cuando el primero ya había fundado su célebre empresa de diseño. A partir de los preceptos de William Morris, De Morgan comenzó a desarrollar una producción cerámica de gran calidad, utilizando diseños originales, en una época en la que los azulejos y la loza volvieron a estar de moda en la decoración de interiores británicos, especialmente a partir de Exposición Universal de París de 1867. Allí pudieron contemplarse las obras de las dos manufacturas de cerámica más importantes de Inglaterra en aquel periodo: Minton y Coppeland, las cuales desarrollaron amplios repertorios de azulejos de aplicación arquitectónica. Frente a la fabricación a gran escala de estas dos empresas, William de Morgan encontró su nicho de mercado en la producción limitada, contralada en todo momento por él mismo y ejecutada bajo sus diseños de estética historicista (Hamilton, 1997, pp. 22-35).

Tras la citada etapa formativa en la que configuró su personalidad artística, en 1872 estableció su taller en Chelsea, en el número 8 de Cheyne Row, en una residencia llamada Orange House. Los trabajos de esta etapa revelan tempranamente las formas de producción que mantuvo hasta el final de su carrera. Bajo su supervisión trabajaba un equipo de pintores encargados de colorear las piezas, los cuales no podían improvisar ni añadir detalles de elaboración propia en ningún momento. Todo quedaba bajo la dirección del ceramista. En los más de trescientos diseños ejecutados durante esta etapa de Cheyne Row (1872-1882) la influencia de William Morris fue borrándose paulatinamente, para dar paso a una producción en la que la tradición mediterránea -española, italiana y del Próximo Oriente- fue predominante, en unos diseños que aumentaron en complejidad a medida que fue avanzando la década de los años 70. Durante esta etapa ejecutó importantes encargos que contribuyeron a su fama y a darle una cierta prosperidad económica. Por su calidad sobresalen los trabajos llevados a cabo en la residencia londinense de Lord Leighton, que explicamos más adelante por su buen estudio de la cerámica Iznik.

En 1882, siguiendo a Morris, De Morgan trasladó su taller a Merton Abbey, una aldea al sudoeste de Londres, con el objetivo de conseguir un alquiler más 
económico y poder utilizar para sus manufacturas las aguas del Wandle, un afluente del Támesis. Aprovechó un antiguo cottage de piedra para instalar su empresa. Aquí mejoró la calidad de sus hornos y creó cerámicas esmaltadas con detallados diseños realizados a mano (Goodman, 200, pp. 16-20). Sin embargo, el largo trayecto diario hasta su taller acabó motivando a De Morgan a buscar en 1887 otro emplazamiento en Fulham, a orillas del Támesis al oeste de Londres. Allí estableció una empresa llamada Sands End Pottery, asociándose con un arquitecto, Halsey Ricardo (1854-1928), célebre por haber aplicado a las residencias burguesas azulejos de cerámica esmaltada al exterior, un material especialmente eficaz frente a la contaminación propia de las urbes inglesas del XIX. Así se aprecia, por ejemplo, en Debenham House, concluida en 1907, un proyecto de Ricardo y De Morgan en Kensington, uno de los mejores ejemplos de la influencia de la arquitectura italiana del Renacimiento en la obra de ambos artistas. Además, en 1887 contrajo matrimonio con la pintora prerrafaelita Evelyn de Morgan (1855-1919), una exitosa artista con la que el ceramista compartió bastantes intereses estéticos. Sin embargo, los problemas de salud de William de Morgan llevarían al matrimonio a establecerse en la ciudad de Florencia, desde donde era complicado mantener la empresa que compartía con Ricardo.

Durante este periodo, el ceramista siguió trabajando en la mejora de sus técnicas, culminado sus investigaciones en 1892, año en el que dio una brillante conferencia en la Royal Society of Arts de Londres sobre la loza dorada, un tipo de cerámica de tradición islámica que intentó emular a lo largo de su carrera (De Morgan, 1892, pp. 756-764). El texto de dicha conferencia, publicado en el Society's Journal, constituye un documento muy elocuente sobre el conocimiento que el artista poseía de la cerámica española, persa y otomana.

Reflejo del interés que la cerámica islámica despertó en William de Morgan hasta el final de sus días, es su proyecto de crear una manufactura de loza de reflejo metálico en Egipto, recogido en su informe presentado al gobierno egipcio: Report on the Feasibility of A Manufacture of Glazed Pottery in Egypt (De Morgan, 1894). Buena parte de la documentación generada sobre este proyecto inconcluso se conserva en la British Library de Londres ${ }^{4}$. Esta empresa, poco difundida todavía, tuvo su origen en un viaje que William de Morgan hizo a Egipto en 1893, comisionado por el gobierno para llevar a cabo una labor de asesoramiento sobre cerámica. Fue Thomas Armstrong, el director del South Kensington Museum el que recomendó a De Morgan al gobierno egipcio. A pesar de su breve estancia en Egipto -según Hamilton (1997, p. 75) no fue superior a tres semanas-, su informe para establecer allí una manufactura moderna detallaba costes, tipos de arcillas, esmaltes, hornos, etc. Sin embargo, el carbón era muy costoso de importar y sin él era complicado

4 BL. British Library. Londres, Reino Unido. Trade and Commerce/Report on proposed glazed pottery manufacture in Egypt, W. De Morgan: 1892-1893. 
alcanzar las temperaturas necesarias para la cocción de la cerámica moderna, rechazando la utilización de técnicas locales. Sus dos contactos en El Cairo fueron el pasha Yacoub Artin -un político de origen armenio, cristiano ortodoxo, que trabajaba para el Ministerio de Instrucción Pública ${ }^{5}$ - y Douglas Dunlop ${ }^{6}$, un docente escocés establecido en la capital egipcia, donde promovió una reforma educativa muy contestada por los nacionalistas egipcios, al marginar el árabe como lengua vehicular en la enseñanza. En definitiva, el plan de William de Morgan en Egipto fue una muestra de cómo el gobierno probritánico deseaba modernizar las manufacturas locales a través de métodos ajenos a la producción tradicional egipcia, lo que unido a la mala salud de De Morgan, asentado en Florencia por aquel entonces, frustró el proyecto.

Por otro lado, la sociedad Morgan-Ricardo acabó disolviéndose en 1898 y Sands End cerró sus puertas definitivamente en 1907. De Morgan falleció diez años después, cediendo su esposa Evelyn más de 1200 objetos y diseños del autor al V\&A de Londres ${ }^{7}$.

\section{GLAZED POTTERY: DISEÑOS DE INSPIRACIÓN ISLÁMICA EN LA OBRA DE WILLIAM DE MORGAN}

A continuación, explicamos cómo se tradujo esa fascinación por la cerámica de inspiración islámica en la obra de William de Morgan. Para adentrarnos en esta cuestión contamos con una información indispensable, el citado discurso pronunciado por el ceramista en la Royal Society of Arts en 1892. El texto posee un gran valor para evaluar cuál era el conocimiento que se tenía en la Inglaterra victoriana sobre la historia de la cerámica de reflejo dorado, además de demostrar la erudición de este ceramista, para quien la investigación histórica no podía desvincularse de su práctica creativa. A lo largo del escrito cita las obras de otros ceramistas que conoce y aprecia, como Théodore Deck o Clement Wedgwood. También explica que, hacia 18731874 durante su etapa en Cheyne Row, ya consiguió una fórmula bastante adecuada para ejecución de un reflejo metálico similar al de la cerámica de tradición islámica. Afirma que no modificó sustancialmente esa composición, pero sí continuó realizando abundantes experimentos con compuestos químicos, muchos de ellos sin buenos resultados, como resume hacia el final del artículo. Otro aspecto interesante que co-

${ }^{5}$ BL. British Library. Londres, Reino Unido. Trade and Commerce/Carta de Yakub Artin a William de Morgan: f. 56.

${ }^{6}$ BL. British Library. Londres, Reino Unido. Trade and Commerce/Cartas de Douglas Dunlop a William de Mogan: ff. 50, 55, 59, 63, 65, 68.

7 Las piezas ingresaron en el V\&A en 1919 y constituyen una fuente de primer orden para la investigación sobre la cerámica británica de la segunda mitad del siglo XIX. 
menta De Morgan es su intención de diferenciarse de las obras históricas. Partiendo de la tradición medieval pretende crear piezas originales, propias de su tiempo. En ello se distingue de otros ceramistas como el propio Thédore Deck, a quienes interesaba más la copia de objetos antiguos, tal y como se aprecia en sus reproducciones de piezas Iznik o de los vasos de la Alhambra. Al principio del artículo, De Morgan define lo que para él es el reflejo «lustre» en la cerámica, señalando que se trata del depósito de componentes metálicos sobre una superficie esmaltada, en la que el resultado decorativo depende de reflejar o no luz sobre el objeto.

Partiendo de estos preceptos, podemos abordar las diferentes influencias que el artista extrajo de la cerámica islámica. Podemos dividir las referencias de William de Morgan en tres grandes grupos, las obras de inspiración persa, las realizadas al estilo Iznik y las que seguían la corriente hispanomusulmana.

En época victoriana, bajo la denominación de cerámica persa se englobaban las tradiciones persa, otomana (Iznik), siria y egipcia. Robert Murdoch Smith publicó en 1877 un libro titulado Persian Art, en el que reflejó sus estudios sobre el arte persa, dedicando un capítulo a la cerámica. Para Smith, el arte islámico debía al persa la sofisticación de sus formas, pues frente a la tradición beduina árabe, los primeros musulmanes que llegaron a Persia encontraron una civilización con una arquitectura, escultura y artes decorativas muy desarrolladas, las cuales, según Smith, exportarían a Al-Ándalus y de allí al resto del mundo musulmán.

Estas piezas del arte antiguo, junto a numerosos monumentos islámicos de Persia, fueron difundidas en dos publicaciones realizadas en los años 80 por la arqueóloga Jane Dieulafoy (1887 y 1888), obras que tuvieron una amplia difusión y en cuyas ilustraciones se aprecian numerosas cerámicas persas.

Aun así, Smith señala una personalidad propia para la cerámica persa, muy influenciada por la llegada de piezas de porcelana china a través de la Ruta de la Seda, como sucedía para la Iznik. La época de mayor esplendor de la loza persa fue la correspondiente al gobierno del Shah Abás el Grande (1588-1629), a partir del cual la producción fue decayendo (Smith, 1877, p. 8). El autor describió detalladamente hasta seis tipos de cerámica persa distintos, indicando sus componentes químicos y sus motivos decorativos, constituyendo una fuente de información bastante ajustada que De Morgan conoció y tuvo en cuenta a la hora de crear su producción. Un elemento muy característico del arte persa desde la Antigüedad era la cerámica esmaltada aplicada a la arquitectura. William de Morgan conocía los envíos de coloridas terracotas esmaltadas que el matrimonio Dieulafoy había mandado desde el palacio de Darío en Susa hasta el Museo del Louvre. Los azulejos persas para la ornamentación de edificios eran, según Smith, creaciones de intrínseca belleza, muy adecuadas para su finalidad decorativa.

Por lo tanto, William de Morgan contó con fuentes precisas sobre la cerámica iraní. Además de la influencia de la cerámica persa antigua, ya representada en el South Kensington Museum en los años 70 del siglo XIX (Smith, 1877, p. 17), 


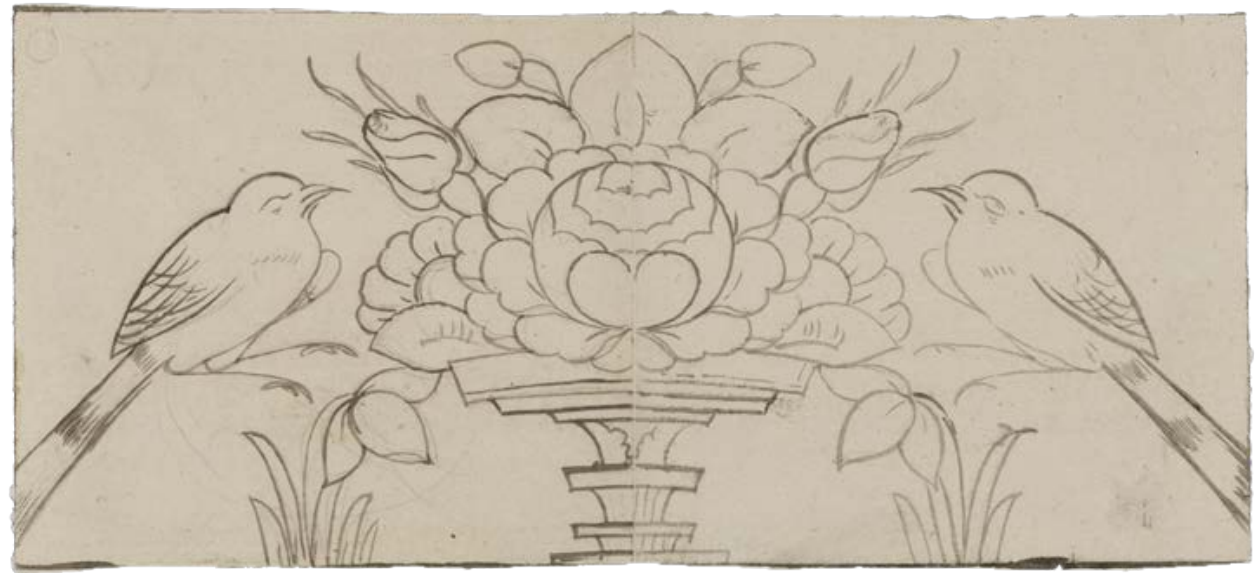

Fig. 3. Diseño para aplicación arquitectónica (1840-1870). Mirza Akbar. Fotografía gentileza del @ Victoria and Albert Museum, London.

De Morgan tuvo que conocer las piezas de cerámica producidas en Teherán en época contemporánea, en ocasiones por encargo de occidentales. Así, el Victoria and Albert conserva varios paneles elaborados en un barrio de alfares ubicado al sur de la capital, para el compositor francés Albert Lemaire, residente en Irán desde 1868. Estos paneles eran imitación de piezas medievales elaboradas para la decoración de edificios. De Morgan conoció necesariamente este tipo de cerámica, tomando de ella motivos vegetales como las hojas o los árboles persas (Greenwood, 2007, p. 12). Otra fuente importante que De Morgan pudo conocer fueron los dibujos ejecutados por Mirza Akbar, arquitecto de la corte de Teherán a mediados del XIX, que presentó al británico Caspar Purdon Clarke un libro de diseños persas adquirido por el South Kensington Museum en 1875 (Carey, 2018, pp. 47-67). Una parte importante de este conjunto de 238 diseños ejecutados sobre papel corresponde a motivos geométricos. Sin embargo, en los restantes, las representaciones de animales como venados, aves y multitud de composiciones vegetales, ofrecen un repertorio muy versátil para ser reproducido en piezas cerámicas o papeles pintados.

Hemos podido localizar figuras representadas por De Morgan en sus diseños ejecutados a la acuarela sobre papel que guardan una correspondencia directa con el repertorio de Mirza Akbar, accesible al ceramista en sus visitas al South Kensington Museum. Así, se aprecia en la plasmación de motivos zoomorfos, de los cuales las representaciones de pequeñas aves son casi idénticas, tal y como comprobamos en un diseño de Mirza Akbar de dos pájaros apoyados sobre unas flores dispuestos en perfecta simetría axial (AL.8287:6, Fig. 3) y un dibujo de un pájaro posado sobre flores persas ejecutado por De Morgan (E.1574-1917, Fig. 4). Del mismo modo, estas figuras recuerdan a uno de los diseños para textil y papel pintado más famosos de William Morris, el denominado The Strawberry Thief, inspirado en los tapices 


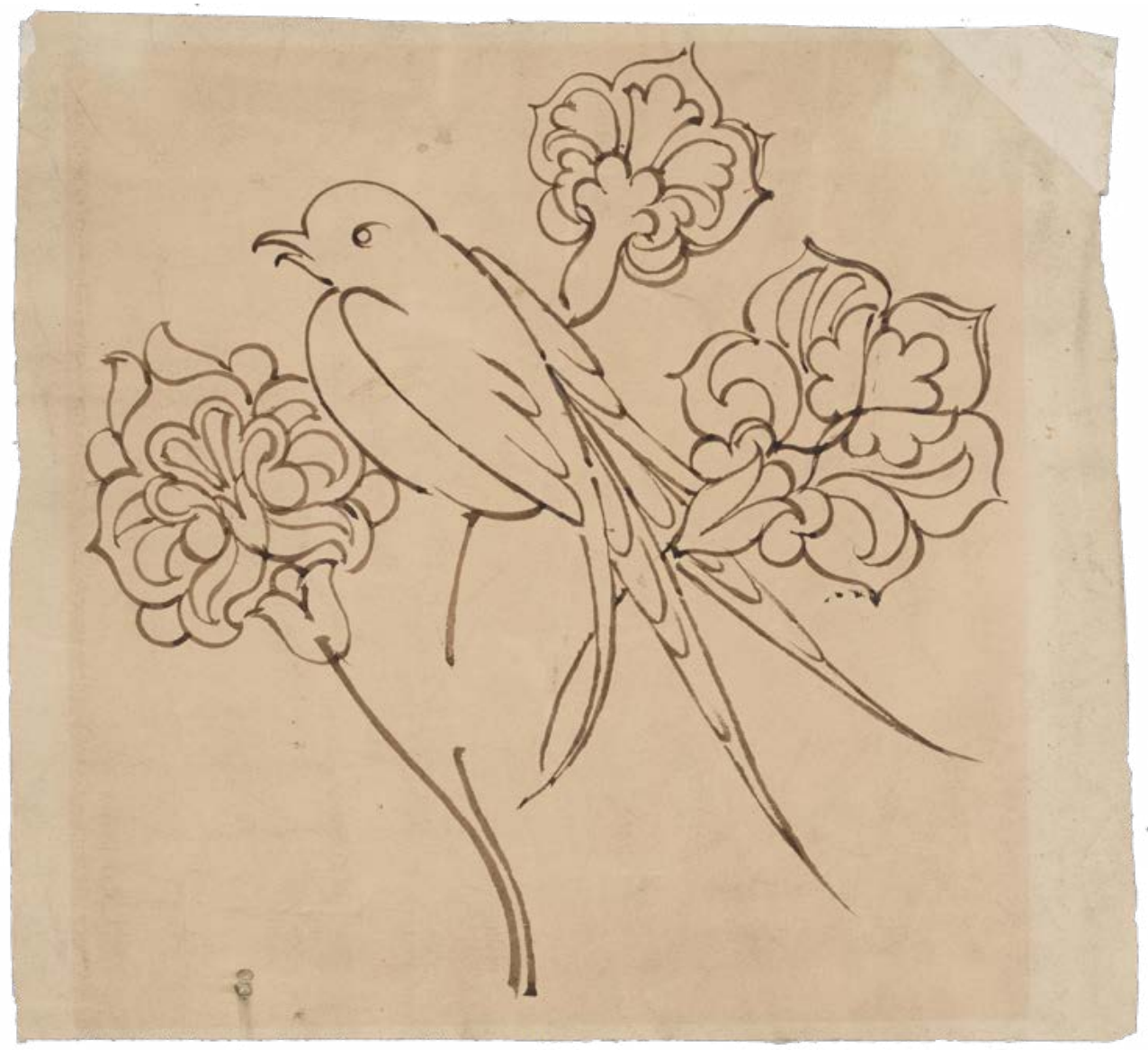

Fig. 4. Diseño zoomorfo (f. S. XIX). William de Morgan. Fotografía gentileza del (C) Victoria and Albert Museum, London.

europeos medievales (Harris, 2018, p. 170), pero también caracterizado por esa simetría axial propia de los patrones del arte islámico que permite prolongarlos a demanda del diseñador.

Los diseños zoomorfos son una parte importantísima en la producción de WiIliam de Morgan. Además de las aves, otro motivo muy representado son los venados, tratados con una gran estilización, dibujados con sencillos trazos que remiten, de nuevo, a modelos del arte persa. Los venados en movimiento aparecen grácilmente representados en cerámicas iraníes medievales, como apreciamos en un plato del V\&A procedente de Kashan, Irán, fechado en el siglo XIII, un temprano ejemplo de loza dorada (C.164-1977). Esta forma tan esquemática de representación de los venados se mantuvo a lo largo de los siglos en la plástica persa y la apreciamos de nuevo en los dibujos de Mirza Akbar (AL.8287:1, Fig. 5) y en múltiples diseños y piezas elaboradas por William de Morgan (ej. E.1203-1917, Fig. 6). 


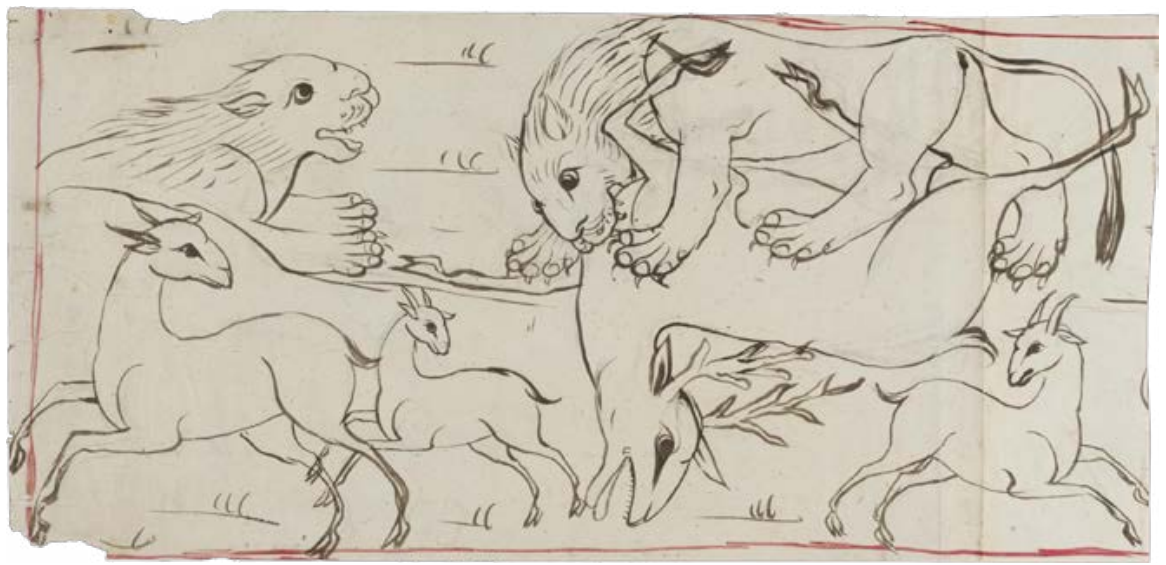

Fig. 5. Diseño para aplicación arquitectónica (1840-1870). Mirza Akbar. Fotografía gentileza del @ Victoria and Albert Museum, London.

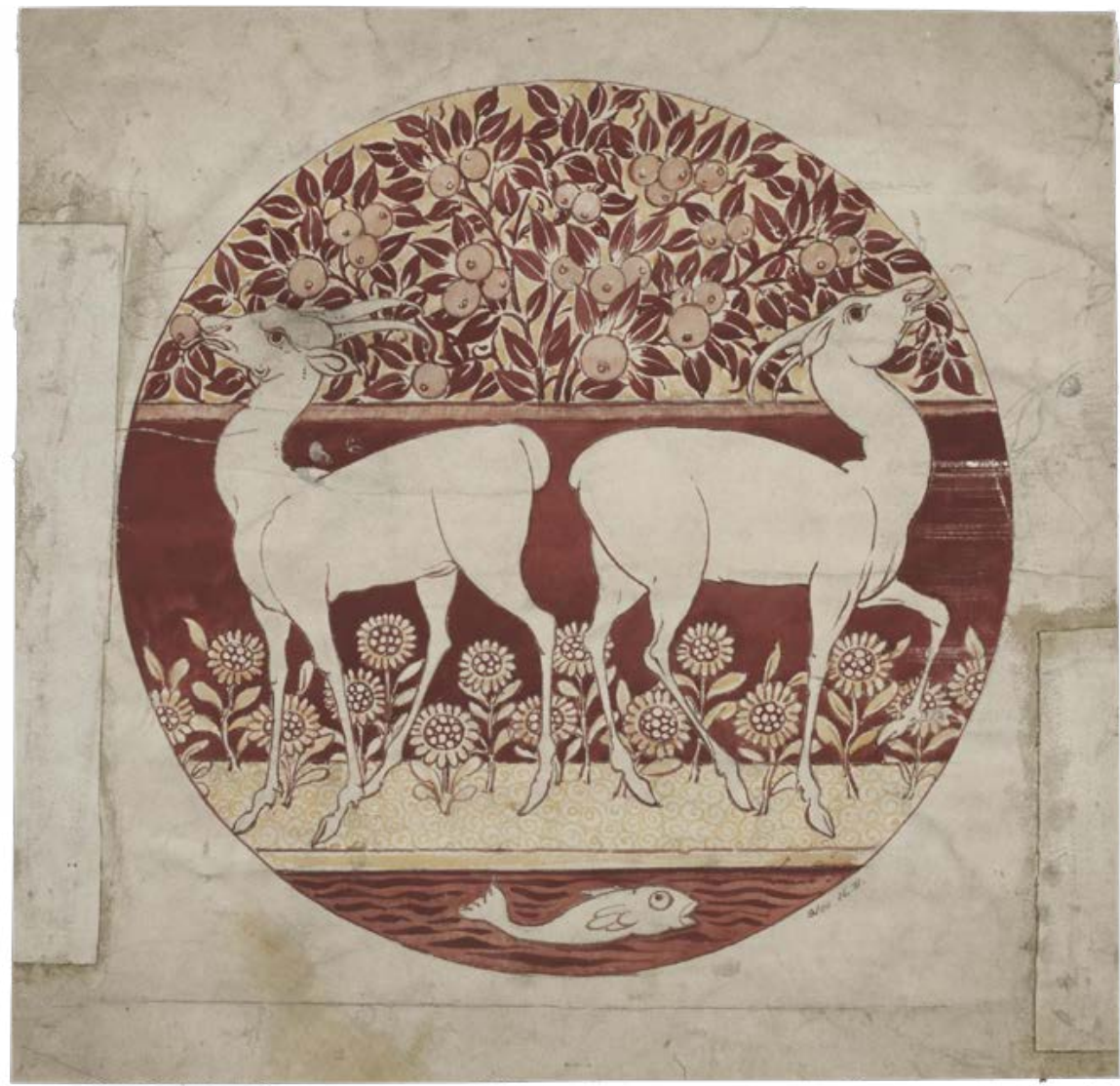

Fig. 6. Diseño de plato con ciervos, frutales y peces (1881). William De Morgan. Fotografía gentileza del (C) Victoria and Albert Museum, London. 


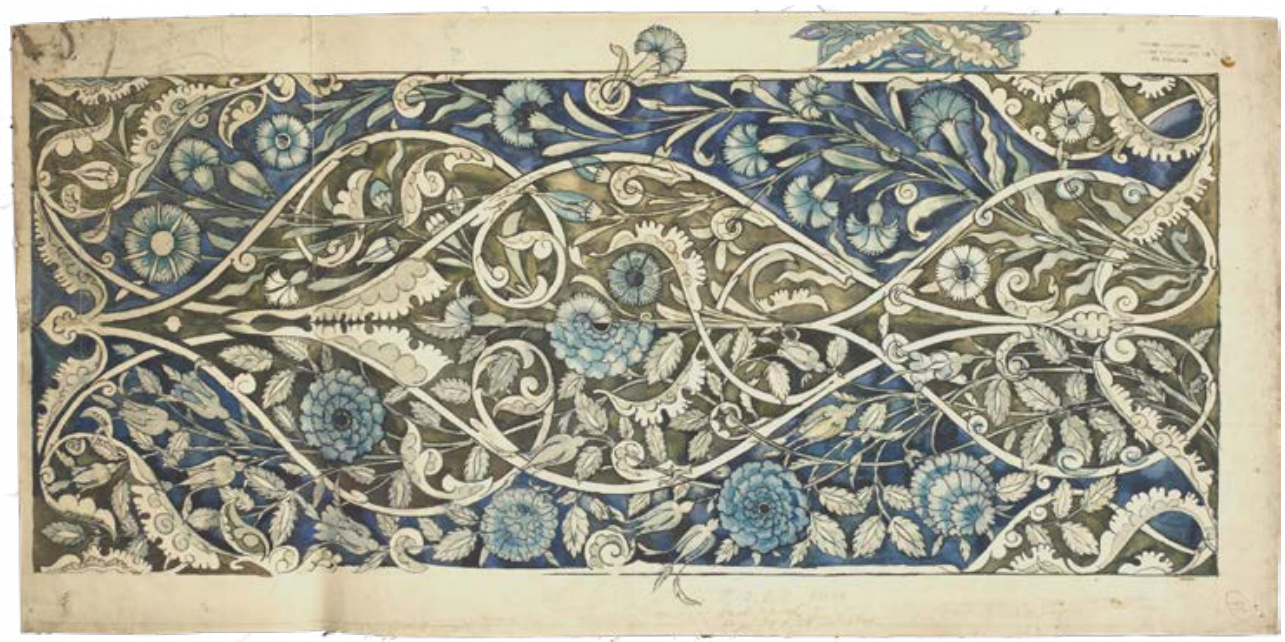

Fig. 7. Diseño, probablemente para un panel de azulejos. Patrón de follaje persa (f. s. XIX). William de Morgan. Fotografía gentileza del (c) Victoria and Albert Museum, London.

El arte persa dio a William de Morgan un repertorio zoomorfo que no podía encontrar tan fácilmente en la cerámica Iznik o en la hispanomusulmana, donde la condición anicónica del arte islámico por la que no se representaban seres animados era más potente. Además, el ceramista estudió detenidamente los diseños florales tanto del repertorio de Mirza Akbar como de los ejemplos de cerámicas existentes en el South Kensington Museum, desarrollando decenas de patrones para la elaboración de azulejos y piezas cerámicas con diseños florales. En muchos de los dibujos de William de Morgan (ej. E.422-1917, Fig. 7) la composición en torno a un eje de simetría axial, el decorativismo, las formas representadas y el colorido utilizado, remiten a piezas como las citadas elaboradas en los alfares de Teherán en época contemporánea para la residencia de Albert Lemaire (522:9-1889, Fig. 8).

Por otro lado, y aunque ciertos patrones vegetales fueron compartidos por el arte persa y el arte otomano, podemos distinguir cuáles fueron los elementos que William de Morgan tomó de la cerámica Iznik. Si bien el propio artista catalogó como persas sus diseños inspirados en el arte otomano, esta cerámica era bien conocida en occidente en la segunda mitad del siglo XIX. No olvidemos que en la Exposición Universal de París de 1867 se reprodujo un barrio otomano, con pabellones diseñados en Estambul por el arquitecto francés Léon Parvillée, copiando edificios palaciegos e incluso una mezquita del Bósforo (Çelik, 1992, pp. 95-110). En esos años trabajaron diseñadores y ceramistas franceses como Eugène-Victor Collinot y Adalbert de Beaumont, autores de varios libros de recopilación de ornamentos, entre ellas Ornements de la Perse (1880). En esta obra, además de paneles cerámicos persas, incluyeron cerámicas directamente copiadas de edificios del Imperio Otomano, tal y como vemos en dos azulejos de decoración floral del quiosco de Be- 


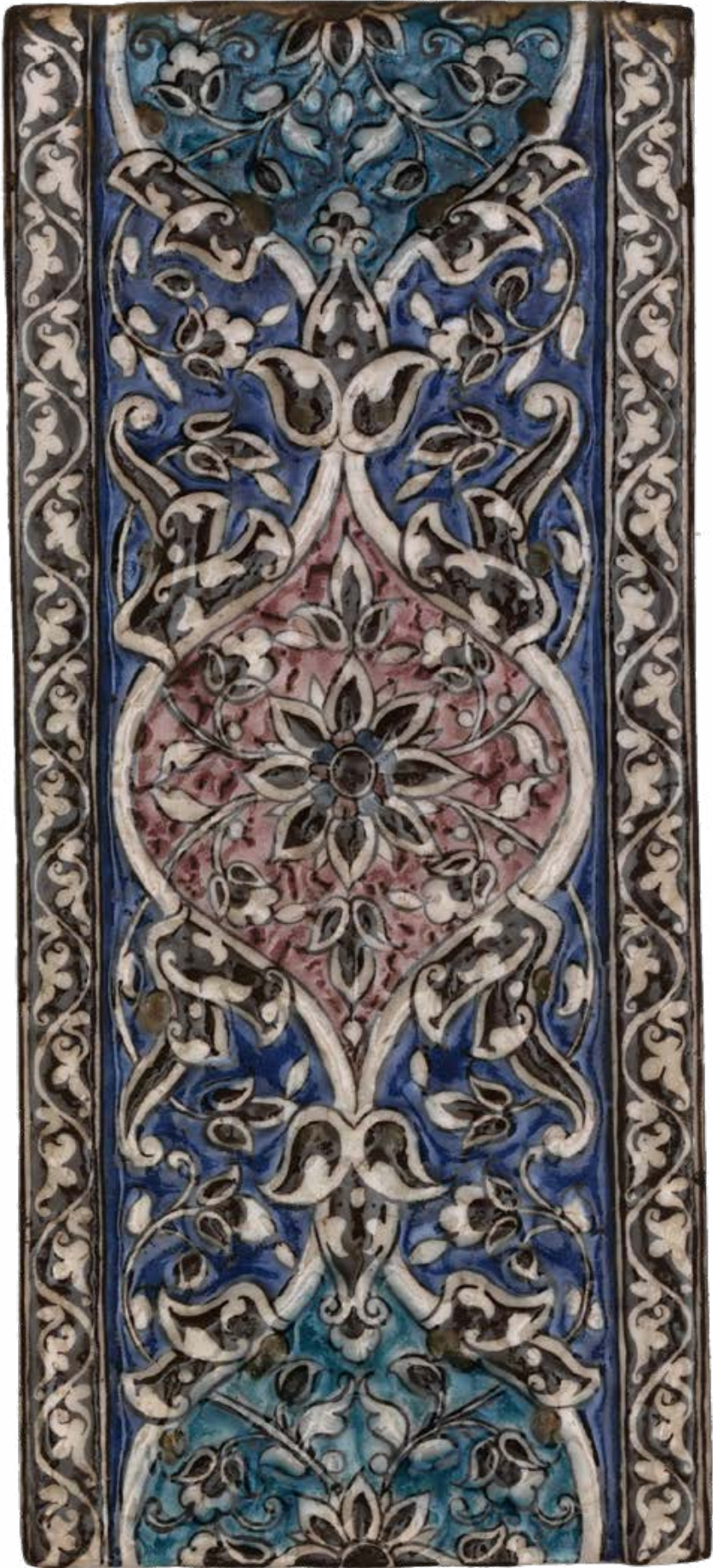

Fig. 8. Azulejo (1884-1885). Ali Muhammad Isfahani. Fotografía gentileza del (C) Victoria and Albert Museum, London. 
ghiktash en Estambul (Collinot y Beaumont, 1880, p. 51). Los dos diseñadores fundaron en 1863 su propia manufactura de cerámica, aprovechando la moda por las artes decorativas de inspiración islámica en Francia. Sin embargo, fue Thédore Deck quien más difundió las piezas de estilo otomano, especialmente a partir de su participación en la Exposición Internacional de Londres de 1862, donde expuso obras que seguían directamente los motivos del arte Iznik (Todd Harlow, 1992, pp. 8-15). El South Kensington Museum adquirió varias de sus creaciones, por lo que William de Morgan pudo conocerlas sin tener que trasladarse a París.

Además, el ceramista pudo contemplar directamente obras de cerámica Iznik originales. Las colecciones estatales británicas se enriquecieron en la segunda mitad del siglo XIX con donaciones como la de John Henderson, un coleccionista aficionado a la arqueología, propietario de uno de los mejores acervos de cerámica islámica de Inglaterra, expuesto en su residencia del barrio de Bloomsbury en Londres (Pinder-Wilson, 1953, p. 59). A su fallecimiento en 1878 estas piezas pasaron al Museo Británico, aunque previamente, hacia 1868, el South Kensington Museum se había interesado por ellas, consiguiendo el citado álbum de fotos de la colección. Además, en 1872, parte de la colección de Henderson fue expuesta en el South Kensington Museum. En las fotografías del álbum la cerámica Iznik recibía la denominación de «Rhodian», haciendo referencia a la isla de Rodas, lugar en el que eran compradas muchas de las piezas. La lámina número 11 del álbum (60160) muestra un interesante conjunto de piezas Iznik, similares a las que William de Morgan ejecutó a partir de los años 80 del siglo XIX.

Sin embargo, serían sus trabajos para la residencia londinense de Frederic Leighton (1830-1896), uno de los pintores más destacados del Aesthetic Movement en Gran Bretaña, los que pondrían a William de Morgan definitivamente en contacto con piezas Iznik. La casa fue diseñada por el arquitecto George Aitchison siguiendo muy de cerca las indicaciones del propietario. Su estancia más destacada era el Arab Hall (Fig. 9), un espacio central que funcionaba a modo de recibidor y de estudio de Leighton, decorado con azulejos adquiridos por el artista en Damasco, la isla de Rodas y Egipto. A nivel arquitectónico, el espacio se muestra heredero de las arquitecturas musulmanas, de hecho, tal y como señaló Mary Roberts (2018), Leighton copió en varios de sus apuntes capiteles de La Zisa, un palacio construido por artistas musulmanes para los reyes normandos de Palermo en el siglo XII, con el que el Arab Hall guarda una estrecha relación. Para hacerse con una cantidad ingente de azulejos, Leighton mantuvo contactos en varios países del Próximo Oriente, siendo determinante la labor del orientalista Richard Burton, asentado en la ciudad de Damasco, donde se estaban arrancando cerámicas de casas antiguas para venderlas a occidentales. Leigthon aprovechó esta circunstancia para conformar su colección, recibiendo varios envíos de piezas que, en ocasiones, llegaron rotas a Inglaterra. Aun así, en 1877 el acervo amasado por el artista era lo suficientemente numeroso como para iniciar la decoración de su Arab Hall. William de Morgan reci- 


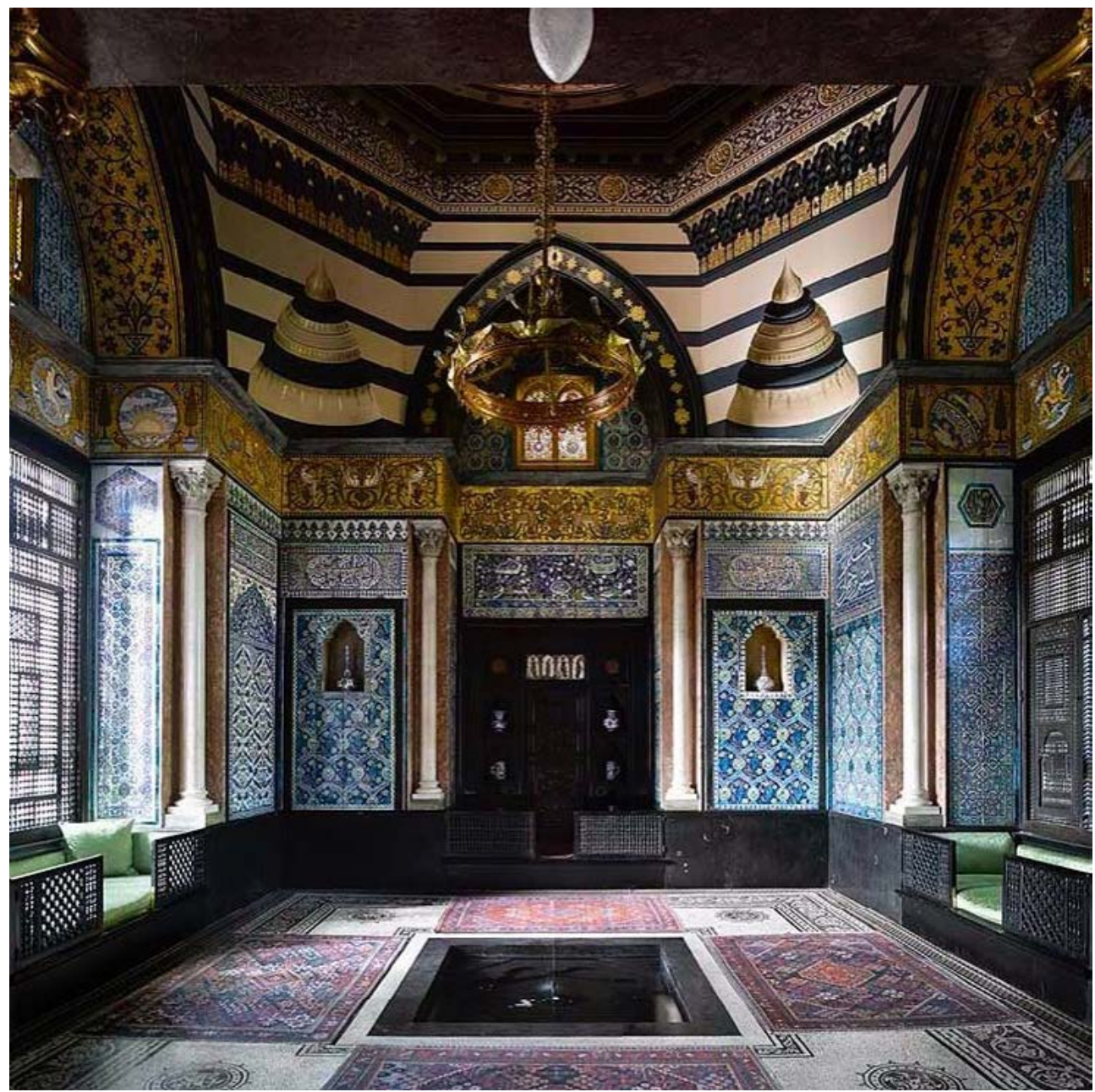

Fig. 9. Arab Hall, Leighton House (f. s. XIX). George Aitchison, William de Morgan y Walter Crane.

bió el encargo de restaurar las piezas fragmentadas y de crear otras nuevas que permitiesen configurar un interior armonioso. La dificultad residía en la gran cantidad de fragmentos de diversa procedencia, cada uno con sus propios ritmos compositivos, difíciles de encajar en un marco arquitectónico preconcebido. El ceramista se enfrentó a este cometido en un estadio todavía temprano de su carrera, por lo que los trabajos aquí realizados le sirvieron para introducir mejoras en su técnica. Mary Roberts explica las dificultades que debió de experimentar tratando de conseguir los perfeccionados acabados de las cerámicas Iznik, logrando un resultado que, si en una visión de conjunto resulta satisfactorio, al analizar detalladamente cada pieza revela imperfecciones, entre ellas bordes poco nítidos, resultado de someter las cerámicas a una temperatura de cocción demasiado elevada. 
A pesar del interés arqueológico de William de Morgan a la hora de restaurar y crear nuevos azulejos, para los invitados de Frederic Leighton que visitaron el Arab Hall, la estancia era un capricho musulmán, un llamativo y sorprendente espacio capaz de transportarles a lugares exóticos. Mary Eliza Haweis en Beautiful Houses (1882), afirma que la estancia le recordaba al Alhambra Court del Crystal Palace de Sydenham Hill, una réplica del patio de los leones del palacio nazarí, construida por Owen Jones en 1854 (Varela, 2017, pp. 71-84). Aun así, su descripción de esta dependencia arroja más datos sobre las fuentes seguidas por sus creadores (Haweis, 1882, pp. 6-7):

Las paredes están revestidas con azulejos sirios de suaves y variados azules y blancos, dispuestos en paneles, montados en un friso ancho, todavía inacabado, diseñado por Walter Crane con un hermoso patrón de cervatillos y viñas, realizado en teselas doradas de Venecia. Por encima se elevan franjas de mármol negro y blanco y encima de nuevo la cúpula dorada.

Walter Crane, un ilustrador y decorador vinculado al movimiento de las Arts \& Crafts, fue el encargado armonizar el conjunto, creando por encima de los azulejos Iznik ese elegante friso de estilo bizantino.

Con el paso de los años, De Morgan perfeccionó sus cerámicas de inspiración otomana, desarrollando diferentes tipologías de vasos, jarras, platos y jarrones. Además, entre sus creaciones más demandadas estuvieron los paneles formados por varios azulejos recreando un dibujo de mandorla, integrada únicamente por flores de diferentes tipos, desde su contorno hasta los detalles del interior. Así se aprecia en algunos paneles cerámicos de mezquitas de Estambul del siglo XVI, como por ejemplo en la de Atik Valide (Fig. 10), en el barrio de Üsküdar, diseñada por el célebre arquitecto imperial Sinan. El esquema fue reproducido por William de Morgan en sus trabajos para la compañía naval The Peninsular and Orient Steam Navigation Co., para la que realizó decoraciones entre 1882 y 1900 . Así lo apreciamos en un panel conservado en el V\&A procedente del navío Sutlej (362:8-1905, Fig. 11), que evidencia el talento del artista para reinterpretar un elemento ornamental propio de la arquitectura otomana del siglo XVı y adaptarlo a la decoración del salón de un barco decimonónico.

Sin embargo, las fuentes directas para De Morgan estaban en su propia ciudad, encontrando magníficos ejemplos de decoración floral en el legado Henderson conservado en el Museo Británico y en las piezas adquiridas por el South Kensington Museum. A pesar de que el ceramista no solía copiar de manera literal los diseños de obras antiguas, en su producción de inspiración otomana podemos llegar a distinguir varias de las especies florales presentes en los ejemplos Iznik, como los claveles, los tulipanes, los jacintos, los lirios o, motivos arbóreos como el ciprés (Khabbazi y Yazgan, 2013, pp. 271-275). 


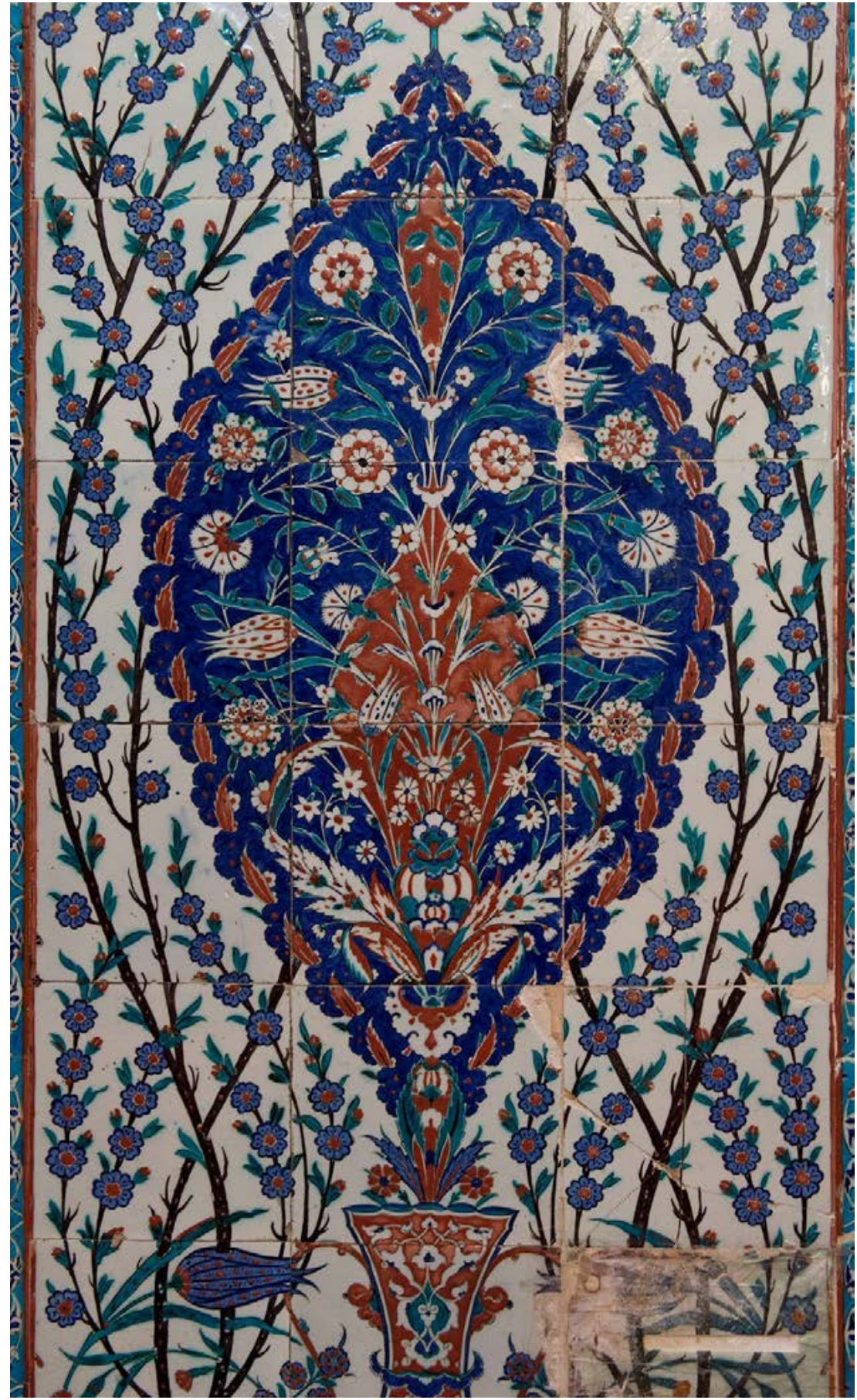

Fig. 10. Panel de azulejos Iznik, Mezquita de Atik Valide, Estambul (s. xvI). Dominio público. 


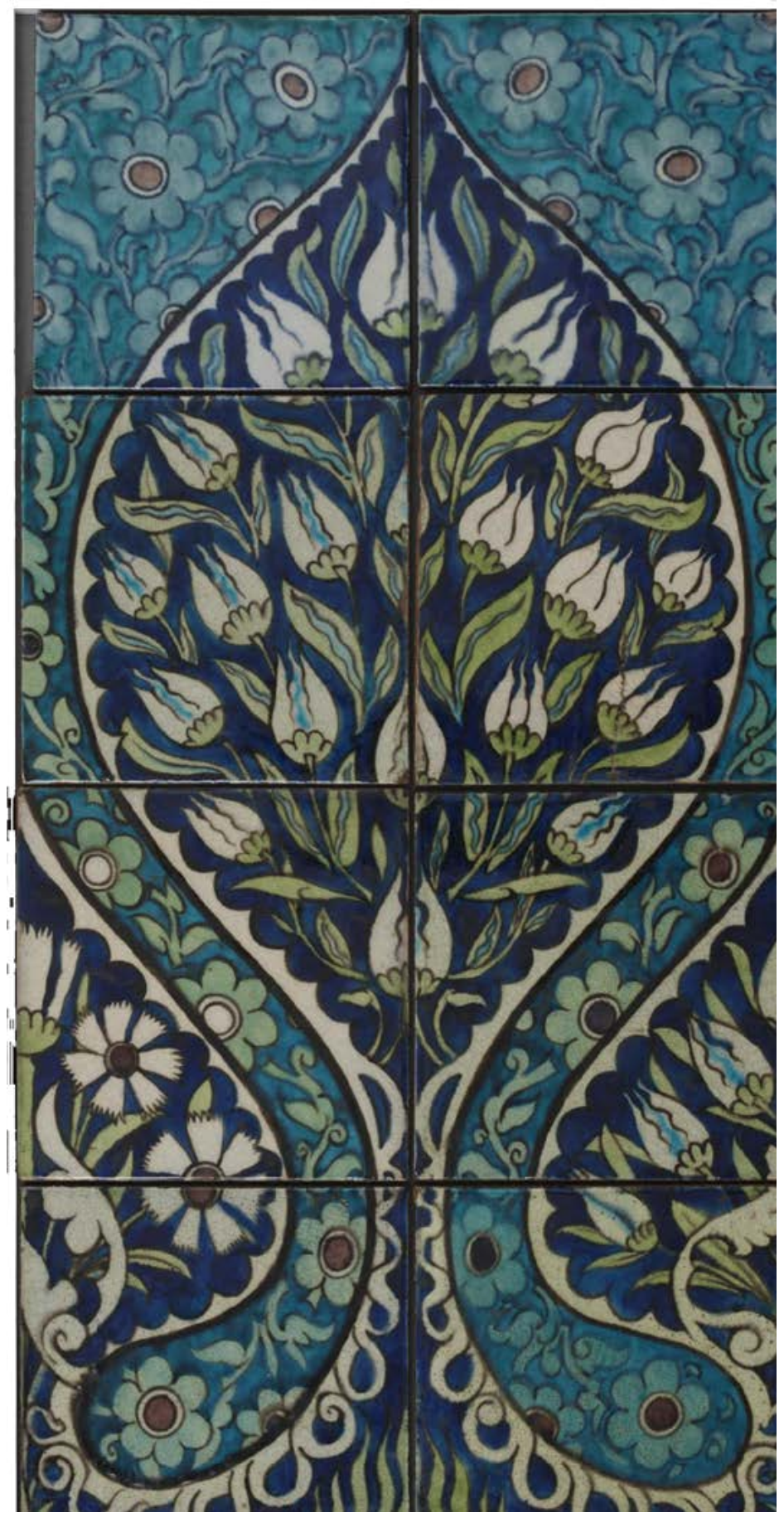

Fig. 11. Panel de azulejos (ca. 1882). William de Morgan. Fotografía gentileza del (C) Victoria and Albert Museum, London. 
La última influencia de las cerámicas de tradición islámica que podemos identificar en William de Morgan es la de las piezas hispanomusulmanas. Si bien en las últimas décadas han surgido investigaciones sobre el historicismo en la cerámica española del siglo XIX (véase Rubio Celada 1999 y 2016), todavía carecemos de estudios de conjunto que aborden la influencia que la cerámica andalusí tuvo en la obra de ceramistas europeos decimonónicos. De Morgan admiraba profundamente las piezas producidas en Al-Ándalus y en los reinos cristianos durante los siglos inmediatamente posteriores a la Reconquista, cuando la tradición musulmana se mantuvo en los alfares mudéjares de Paterna, Manises, Toledo, Muel, etc. En el discurso pronunciado en la Royal Society of Arts en 1892 recordó cómo el geógrafo Edrisi situó ejemplos tempranos de reflejo metálico en la cerámica de Calatayud, en 1154. Sin embargo, se muestra en contra de la creencia imperante en el siglo XIX de que monumentos como la mezquita de Córdoba estuviesen decorados antaño con grandes paños cerámicos. De Morgan explica cómo, en época del Califato, la ornamentación imperante era el mármol, el oro y el marfil. Sitúa el cambio durante el periodo nazarí:

El siguiente hito en la historia de esta cuestión [la historia del reflejo dorado] fue la erección de la Alhambra por los reyes moros de Granada. Los antiguos azulejos que cubren los muros son originales de la fecha de conclusión del edificio, sobre 1350. Deben ser distinguidos de los dispuestos en el monumento cuando fue restaurado por Carlos V en el siglo XVI. Pertenecen al mismo tipo de manufacturas que las geniales jarras encontradas llenas de monedas bajo este edificio. Una famosa, de la que hay una copia de Deck en South Kensington, está todavía en la Alhambra y hay otra similar en un museo de Madrid. Estas y una o dos más son los ejemplos más antiguos del uso del reflejo en España. No hay ninguna necesidad de asumir que fuesen importadas de El Cairo o de Persia, y probablemente debamos adscribir su fabricación a Málaga.

Los vasos de la Alhambra fueron objeto de la admiración e imitación de los artistas decimonónicos. Entre ellos fue muy célebre el Vaso Fortuny, un magnífico ejemplo de cerámica de reflejos dorados, adquirido por el pintor Mariano Fortuny en Granada en 1870. Con la venta de la colección del artista en 1875, el vaso pasó a manos de un coleccionista ruso, quien a su vez lo vendió al Museo del Hermitage. Tal y como señala De Morgan en su discurso, conocía la copia que Théodore Deck hizo del Jarrón de las Gacelas de la Alhambra -una obra maestra de la cerámica andalusí difundida a través de postales y fotografías a finales del siglo XIX y comienzos del Xx- perteneciente desde 1865 a la colección del V\&A (18-1865). Además, también en 1862, Plácido Zuloaga expuso sus obras de damasquinado en la Exposición Universal de Londres, mostrando un vaso de tipología Alhambra ejecutado con esta técnica. Años después, su hermano menor Daniel Zuloaga ejecutó otra copia de un vaso de la Alhambra, que el rey Alfonso xil regaló al káiser de Alemania (Rubio Celada, 1999, p. 351). Todas ellas fueron ejemplo del historicismo presente en las 
artes decorativas españolas de la segunda mitad del siglo XIX (Rodríguez Bernis, 2015, pp. 64-86).

A estas piezas habría que sumar las que el South Kensington Museum compró resultado del asesoramiento de Juan Facundo Riaño y a las que De Morgan pudo conocer a través de colecciones privadas como la de George Salting.

A través de estas fuentes, De Morgan estudió la cerámica andalusí atendiendo a dos cuestiones. La primera fue el interés que mantuvo a lo largo de toda su vida por la cuestión del reflejo metálico, un efecto que los alfares andalusíes y mudéjares habían llevado a la perfección a finales de la Edad Media y comienzos de la Edad Moderna. Por otra parte, William de Morgan estudió la tipología de plato ornamental de grandes dimensiones, que hacia los siglos XV y XVI comenzó a decorarse con motivos heráldicos, zoomorfos y, en el caso de la cerámica malagueña, con unas características representaciones de navíos. Este último motivo resultó muy versátil para el artista por su fácil adaptación al formato redondo del plato. Lo apreciamos en muchas de sus obras acabadas y también en algunos de los dibujos preparatorios conservados en el V\&A. En 1864 había ingresado en el South Kensington Museum un magnífico ejemplo de loza de reflejo metálico color cobre (4861864), procedente de los alfares de Málaga, cuando la ciudad todavía estaba bajo dominación musulmana en la primera mitad del siglo xV. Este plato de enormes dimensiones (51,2 cm de diámetro) debió de ser conocido por William de Morgan pues, desde su llegada al museo, fue entendido como una de las piezas más valiosas de la colección de cerámica, por su calidad y buen estado de conservación. Además, el motivo del navío era muy característico de la cerámica musulmana, con ejemplos tempranos constatables en piezas encontradas en la ciudad de Pisa, realizadas en Mallorca en el siglo xı (Rosselló Bordoy, 1992, p. 361). Estos detalles arqueológicos sobre el comercio de cerámica entre Al-Ándalus e Italia eran conocidos por De Morgan, tal y como referenció en su discurso para la Royal Society of Arts. El ceramista representó navíos en muchas de sus obras, existiendo ejemplos como un plato (C.250-2018) y un cuenco (C.78-1923, Fig. 12) conservados en el V\&A que resultan especialmente deudores de la figuración hispanomusulmana, por la adaptación del navío al formato de la pieza, con grandes velas y una quilla curvilínea. Para el plato el artista introdujo peces en las aguas del mar, igual que en el ejemplo malagueño.

Además de la cerámica malagueña, De Morgan conoció las piezas de Manises, herederas de las anteriores en su trabajo del reflejo metálico. Los magníficos ejemplos conservados en Inglaterra sirvieron al artista para completar sus investigaciones sobre el reflejo, realizando figuraciones que encontramos en piezas españolas y también en las italianas del siglo XVI: motivos heráldicos, zoomorfos y animales fantásticos como dragones. Así, encontramos bastante similitud entre los esquemáticos leones rampantes y los simplificados motivos vegetales de las piezas de Manises y los creados por el ceramista inglés (véanse E.1096-1917 o C.425-1919). 


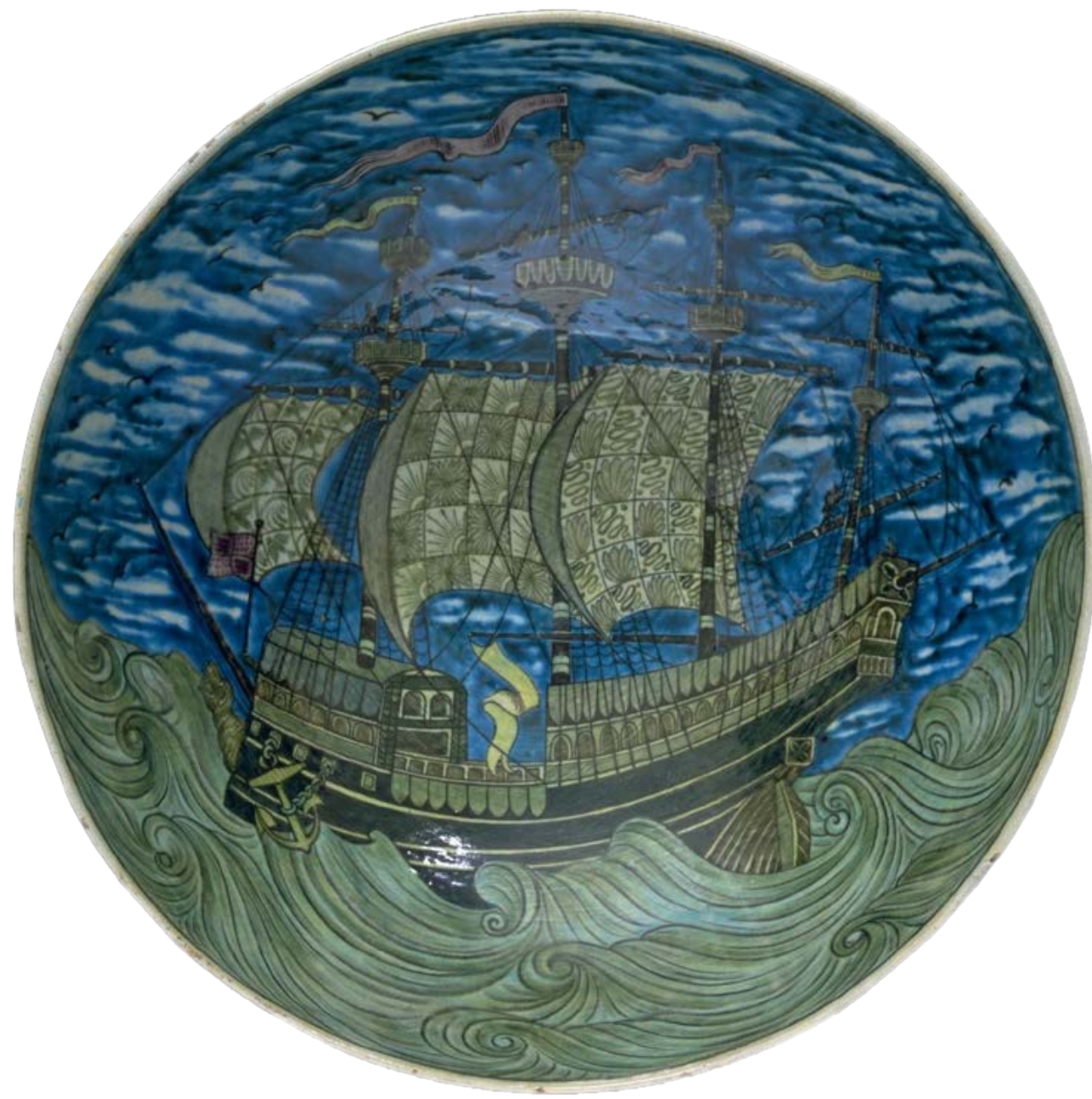

Fig. 12. Cuenco con motivo de navío (1900). William de Morgan. Fotografía gentileza del (C) Victoria and Albert Museum, London.

El objeto de las investigaciones del ceramista nunca fue la reproducción al milímetro de ejemplares históricos, sino la documentación para la creación de obras originales de alta calidad, susceptibles de ser adquiridas para el embellecimiento de los hogares burgueses británicos, en una época en la que el historicismo se encontraba muy presente en la decoración de interiores. Sin embargo, además de las dificultades surgidas con el establecimiento del ceramista en Italia y la gestión a distancia de su taller, cuestiones estéticas también influyeron en su decadencia, pues a comienzos del siglo $x x$ el orientalismo que siguió siendo fructífero en la pintura $-y$ que de hecho viviría una nueva edad dorada con Matisse o Klee-, acabó pasando de moda en las artes decorativas, siendo sustituido por la estética del Art Nouveau. 


\section{CONCLUSIONES}

A lo largo del presente artículo hemos señalado cuáles fueron las principales fuentes de inspiración de William de Morgan a la hora de producir sus piezas de inspiración islámica. Analizando detalladamente cada corriente, podemos comprobar como su producción fue ejecutada sobre unas bases teóricas y estilísticas resultado de una profunda investigación, que no podemos comprender sin establecer comparaciones con objetos adquiridos en Gran Bretaña durante la época victoriana. De esta manera, hemos ahondado sobre los referentes seguidos por los artistas y diseñadores de este periodo, poniendo en valor los modelos que el arte islámico ofreció a estos creadores.

Por otra parte, William de Morgan ha permanecido a la sombra de otros integrantes del movimiento de las Arts \& Crafts y, sin embargo, sus trabajos constituyen un valioso testimonio sobre las corrientes artísticas imperantes en la Inglaterra de la segunda mitad del XIX, especialmente del Aesthetic Movement y del Orientalismo. En relación a esta última, sería necesario seguir profundizando en las revisiones que en el siglo XIX se hicieron del arte islámico, pues en buena medida fueron responsables de la visión que Occidente tuvo del mundo musulmán hasta bien entrado el siglo $\mathrm{xx}$.

\section{REFERENCIAS BIBLIOGRÁFICAS}

Carswell, J. (2006). Iznik pottery. Londres: British Museum Press.

Çelik, Z. (1992). Displaying the Orient: Architecture of Islam at Nineteenth-Century World's Fairs. Berkeley: University of California Press.

Collinot, E. y De Beaumont A. (1880). Ornements de la Perse. Recueil de dessins pour l'art et l'industrie gravés. París: Canson et Cie.

De Fusco, R. (2005). Historia del diseño. Barcelona: Santa \& Cole.

De Guise, L. (2008). Beyond Orientalism: How the West was won over by Islamic Arts. Kuala Lumpur: Islamic Arts Museum.

De Morgan, W. (1892). Lustre ware. Journal of the Society for Arts, 40(2066), pp. 756-764.

De Morgan, W. (1894). Report on the Feasibility of A Manufacture of Glazed Pottery in Egypt. El Cairo: National Printing Office. 
Denny, W. B. (2004). Iznik: the Artistry of Ottoman Ceramics. Londres: Thames \& Hudson.

Dieulafoy, J. (1887). La Perse, la Chaldée et la Susiane. París: Hachette.

Dieulafoy, J. (1888). A Suse, journal des fouilles 1884-1886. París: Hachette.

Fortnum, C. D. E. (1873). A descriptive catalogue of the maiolica Hispano-Moresco, Persian, Damascus, and Rhodian wares in the South Kensington Museum: with historical notes, marks, \& monograms. Londres: South Kensington Museum.

Gadoin, I. (2012). George Salting (1835-1909) and the discovery of Islamic ceramics in 19th-century England. Miranda, (7). http://journals.openedition.org/ miranda/4468. https://doi.org/10.4000/miranda.4468.

González Pérez, A. (2017). Las maquetas de la Alhambra en el siglo XIX: Una fuente de difusión y de información acerca del conjunto Nazarí (tesis doctoral). Madrid: Universidad Autónoma de Madrid.

Goodman, J. (2000). William De Morgan at Merton Abbey. Journal of William Morris Studies, 13(4), pp. 16-20.

Greenhalgh, P. (2000). Le Style Anglais: English Roorts of the New Art. En P. Greenhalgh, Art Nouveau 1890-1914 (pp. 127-145). Londres: V\&A Publications.

Harris, J. (2018). Más sugerentes que imitativos: tejidos y papeles pintados del movimiento Arts and Crafts. En M. Fontán del Junco y M. Zozaya Álvarez (Eds.), William Morris y compañía: el movimiento Arts\&Crafts en Gran Bretaña (pp. 167-183). Madrid: Fundación Juan March.

Haweis, M. E. (1882). Sir Frederick Leighton's House. En M. E. Haweis, Beautiful Houses; Being a Description of Certain Well-Known Artistic Houses (pp. 1-12). Londres: Sampson Low.

Khabbazi, P. A. y Yazgan, M. E. (2013). Usage of ornamental plants in Iznik tiles. En I. Baktur, W. B. Miller y R. Kamenetsky (Eds.), Proceedings of the Eleventh International Symposium on Flower Bulbs and Herbaceous Perennials (pp. 271-274). Antalya: ISHS Section Ornamental Plants. https://doi.org/10.17660/ ActaHortic.2013.1002.34. 
Masuya, T. (2000). Persian Tiles on European Walls. Collecting Ikhanid Tiles in Nineteenth-Century Europe. Ars Orientalis, (30), pp. 39-54

Moya, C. (2018). Persian Art. Collecting the Arts of Iran for the V\&A. Londres: Victoria and Albert Museum.

Newton, C. (1999). Victorian dressings for the home. Nueva York: Harry N. Abrams.

Pinder Wilson, R. H. (1953). John Henderson (1797-1878). The British Museum Quarterly, 18(2), pp. 59-60. https://doi.org/10.2307/4422426.

Raquejo Grado, T. (1988). Un catálogo de las piezas de la Alhambra y de algunas obras neonazaríes. Cuadernos de arte e iconografía, 1(1), pp. 201-244.

Riaño y Montero, J. F. (1872). Classified and Descriptive Catalogue of the Art Objects of Spanish Production in the South Kensington Museum. Londres: South Kensington Museum.

Roberts, M. (2018). The Resistant Materiality of Frederic Leighton's Arab Hall. British Art Studies, (09). https://www.britishartstudies.ac.uk/issues/issueindex/issue-9/leighton-arab-hall. https://doi.org/10.17658/issn.2058-5462/ issue-09/mroberts.

Rodríguez Bernis, S. (2015). Tradición y modernidad en las artes industriales españolas del historicismo. Además De. Revista on line de artes decorativas y diseño, (1), pp. 64-86. https://doi.org/10.46255/add.2015.1.21.

Roselló Boldoi, G. (1992). Bowl. Nasrid period, 15th century. En J. Dodds (Ed.), AlAndalus: The Art of Islamic Spain (p. 361). Nueva York: Metropolitan Museum of Art.

Rubio Celada, A. (1999). Innovaciones técnicas, estilísticas y temáticas en la cerámica de los Zuloaga. Boletín de la Sociedad Española de Cerámica y Vidrio, 38(4), pp. 345-352. https://doi.org/10.3989/cyv.1999.v38.i4.947.

Rubio Celada, A. (2016). Viaje a través de la cerámica artística contemporánea española del Museo Nacional de Artes Decorativas: una selección de piezas. Madrid: Ministerio de Educación, Cultura y Deporte. 
Todd Harlow, F. (1992). Deck and the islamic style. Saudi Aramco World, 43(4). https://archive.aramcoworld.com/issue/199204/deck.and.the.islamic.style. htm.

Townson, D. (2004). Breve historia de Inglaterra. Madrid: Alianza Editorial.

Trusted, M. (2008). Gayangos's Legacy: His Son-in-Law Juan Facundo Riaño (18291901) and the Victoria and Albert Museum. En C. Álvarez Millán y C. Heide (Eds.), Pascual de Gayangos. A Nineteenth-Century Spanish Arabist (pp. 205-222). Edimburgo: Edinburgh University Press. https://doi.org/10.1017/ CBO9780748635481.011.

Trusted, M. (2010). Access to collections of Spanish art in Britain and Ireland in the eighteen and nineteenth centuries. En N. Glendinning y $\mathrm{H}$. Macartney (Eds.), Spanish Art in Britain and Ireland, 1750-1920: studies in reception (pp. 73-84). Woodbridge: Tamesis.

Valera Braga, A. (2017). How to visit the Alhambra and be home in time for tea: Owen Jones's Alhambra court in the Crystal Palace of Sydenham. En F. Giese y A. Valera Braga (Eds.), A Fashionable Style. Carl von Diebitsch and the Maurische Revival (pp. 71-84). Berna: Peter Lang.

Woodward, E. L. (1982). Historia de Inglaterra. Madrid: Alianza Editorial. 
Página intencionadamente en blanco. 